\title{
La identidad pampina en Rivera Letelier*
}

\author{
Mauricio O stria G onzález \\ Universidad de Concepción \\ E-mail: mostria@udec.cl
}

\section{Resumen}

D esde una perspectiva cultural, la identidad pampina es heterogénea y compleja. Su unidad está dada por el espacio compartido: la pampa calichera en medio del desierto más árido del mundo, y por el trabajo, vinculado en todos sus aspectos a las faenas extractoras del nitrato. El relato salitrero tiene manifestaciones tempranas en los avatares de la G uerra del Pacífico y comienza a adquirir su propia fisonomía con los albores del siglo XX. La escritura de la pampa salitrera registra, testimonia y transforma la realidad del desierto y de los campamentos: ora la muestra con afán de denuncia, ora la evoca como forma de recuperarla amorosamente más allá de la muertereal. Rivera Letelier se inserta en la tradición cultural literaria pampina, pero la renueva y al hacerlo recupera para la narrativa chilena y latinoamericana el ámbito de la pampa como lugar propicio a las más variadas e incrébles historias, desde una perspectiva postmoderna y mestiza.

Palabras claves: Identidad cultural, literatura chilena, novela del salitre, Rivera Letelier.

\section{Abstract}

Thecultural identity of northern Chile's "Pampa" isheterogeneousand complex. Itsunity if granted by a shared geography -the nitrate deposits in the the world's driest desert- and those activities related to nitrate minerals extraction. $\mathrm{N}$ itrate fiction has early samples in nineteen-century Pacific War (C hile versus Peru and Bolivia), and acquires a mature aspect by the beginning of twentieth century. Nitrate-pampa writing registers, witnesses, and transforms the reality of the desert and of the miner's villages, both condemning and evoking its ways of life beyond real death. H ernán Rivera Letelier is part of the Pampa cultural and literary tradition, but hereformulatesit, and in so doing he recovers for Latin American and Chilean fiction the vast Pampa area as a space for varied and incredible stories, in a culturally post-modern an hybrid perspective.

Keywords: Cultural identity, chilean literature, nitrate fiction, Rivera Letelier.

Recibido: 30-03-2005. Aceptado: 27-07-2005.

*Estetrabajo es parte de una investigación auspiciada por FO N D ECYT (Proyecto 1030731). 
1. ¿Se puede hablar de una identidad pampina con relación a la gente que $\perp$ vivió en los campamentos y oficinas en el llamado ciclo del salitre? El término identidad, al menos en un primer momento del análisis, nos remiteal sujeto capaz de conocer, de darse cuenta de su existencia y, por lo tanto, de dar cuenta de sí: la identidad es la igualdad consigo mismo, el reconocimiento de sí como distinto de los otros y del mundo. No obstante, la identidad no se reduce a una "mismidad individual" [Larraín: 22], sino que presupone una relación intersubjetiva y social ${ }^{1}$. La identidad es, pues, necesariamente, una condición a la vez individual y colectiva: se es uno mismo en la medida en que se pertenece a un grupo social. Por fin, "la identidad también presupone la existencia de otrosque tienen modos de vida, valores, costumbres, diferentes"; de modo que "en la construcción de cual quier versión deidentidad, la comparación con el 'otro' y la utilización de mecanismos de diferenciación con el 'otro' juegan un papel fundamental" (Larraín: 32).

El término pampino/a, en cambio, implica una atribución de carácter espacial: la pampa es una región. La palabra región ${ }^{2}$ tiene como referente una porción de mundo, un espacio o entorno en el queel ser humano se sitúa, vivey del que, a menudo, se siente parte. La región es un ámbito, primariamente geográfico, pero también y, fundamentalmente, social y cultural: el ser humano no pertenece simplemente a un territorio, sino a un territorio habitado por otros seres humanos, con los que comparte y construye mundo. D ebe distinguirse, pues, entre 'desierto' y 'pampa'. M ientras el primer término hace referencia a una extensión vacía - el despoblado de Atacama que mienta el Inca G arcilaso- , incapaz de generar identidad, el segundo connota al espacio configurado "por los hombres y mujeres que venidos de los cuatro costados del planeta, se introdujeron en él, lo nombraron, lo construyeron, lo habitaron y hablaron de él en su cotidiano" (G onzález M iranda: 31). Al proyectarse sobre la región, la identidad se torna regionalidad, nacionalidad o, en nuestro caso, 'pampinidad'3. Ese

1 "Los individuos se definen a sí mismos, o se identifican con ciertas cualidades, en términos de ciertas categorías sociales compartidas" (Larraín: 25). Para las distintas nociones de identidad, véase también Vergara Estévez (2003).

2 Para una discusión del concepto de 'región' en el ámbito de los estudios sociales, véase: Arenas y M astrangelo (1987).

3 “Entendemos por 'pampino' a la categoría cultural que identificaba al poblador organizado socialmente en clubes, cofradías, estudiantinas, grupos teatrales, etc.

M ás allá de las definiciones, los hombres y las mujeres que habitaron los cantones, pueblos y campamentos salitreros, verdaderas comunidades urbanas, se definieron como pampinos: el espacio les proporcionó el concepto de la identidad. 'Pampa' en quechua significa una “Ilanura extensa desértica" (González M iranda: 31). 
sentimiento de pertenencia ${ }^{4}$ se funda en los procesos y productos culturales en los que nos reconocemos.

D esde una perspectiva cultural, la identidad pampina es heterogénea y compleja. Su unidad está dada por el espacio compartido: la pampa calichera en medio del desierto más árido del mundo, y por el trabajo, vinculado en todos sus aspectos a las faenas extractoras del nitrato. En ese medio geográfico y laboral se concentran gentes oriundas de muy diferentes lugares, etnias y culturas. Allí se mezclan, entrecruzan einvaden perfiles económicos, sociales y culturales muy disímiles, que se conjuntan para producir una historia compleja, contradictoria y agónica. Son ingleses, americanos, peruanos, bolivianos, chilenos, argentinos, italianos, yugoslavos, árabes y chinos que "trajeron sus formas de vida, sus costumbres, sus lenguas, sus esperanzas de retorno" [G onzález M iranda: 32]; todos en busca de un destino que terminó configurando una identidad cultural perfectamente diferenciada.

H acia 1930, el colapso del precio del salitre inició la crisis definitiva de la industria y de la sociedad que vivía a sus expensas. En poco tiempo, las bullentes oficinas quedaron deshabitadas, convertidas en pueblos fantasmas. Así, la sociedad y la cultura del sal itreal canzaron a durar poco más de un siglo. A pesar de su efímera existencia, surgió en la pampa un espacio cultural nuevo, inédito, propio que tuvo su expresión en formas de comportamiento, organización del trabajo, normas valóricas y en los diversos códigos que organizaron sus formas de vida y sus sistemas de comunicación. Entre ellos, la lengua hubo de acomodarse, especialmente en su léxico, pero también en los otros componentes del sistema, a las nuevas necesidades expresivas de la emergente comunidad cultural, cuya razón de ser afincaba, como queda dicho, en las actividades laborales que constituyeron el eje decisivo de su surgimiento y consolidación, el condicionamiento indispensable de su convivencia social.

La cultura pampina fue una cultura particularmente urbana: las oficinas (emplazamiento de las instalaciones industriales y habitacionales) y campamentos (conjunto de viviendas) fueron pueblos habitados por los trabajadores y sus familias. Los pobladores se organizaron en clubes, cofradías, conjuntos teatrales y musicales, filarmónicas, mutuales, sindicatos. Al mismo tiempo, se estructuró una muy estricta sociedad clasista que se manifestó en la demarcación de los espacios, en las relaciones laborales, en la calidad de vida, en las formas de trata-

\footnotetext{
${ }^{4}$ Afirma con lucidez Fidel Sepúlveda: “La inmensa mayoría mestiza del continente hispanoamericano vive la identidad por pertenencia. Sentimiento humanizador de vinculación a un territorio, a una estirpe, a una tradición. Es una humanidad creada, más que por los acontecimientos consignados como relevantes por la historia, por los acontecimientos generados en el interior de la intrahistoria y en el subsuelo de la transhistoria" [2000: 442].
} 
miento, etc., con repercusiones más allá de la pampa, en los puertos aledaños por donde se exportaba el Ilamado oro blanco ${ }^{5}$. Los espacios que ocupaban las casas de jefes, administrativos y obreros estaban rígidamente demarcados y vedados sus accesos a quienes no pertenecieran por oficio o condición a cada sector. También se segregaba en los lugares públicos (plazas, teatros, escuelas, pulperías) y en las actividades sociales (fiestas, espectáculos).

La cultura pampina fue, desde un comienzo, heterogénea y mestiza: mineros, cateadores y peones del N orte C hico, campesinos del sur, campesinos indígenas del Perú y Bolivia, pobladores de los puertos al edaños, pequeños comerciantes, funcionarios públicos, maestros, policías, administradores, aventure ros, jefes, casi siempre europeos. Aunque era una sociedad mayoritariamente masculina, las mujeres cumplieron importantes roles no sólo como amas de casa: realizaron trabajos en las calicheras, en las 'cantinas' o pensiones, en los grupos artísticos, en las escuelas y también, como prostitutas.

El habla pampina se caracteriza, fundamental mente, por la resemantización y creación de términos referidos a las faenas salitreras. En este sentido, se trata de una jerga que rebautiza y designa lugares y oficios, herramientas y operaciones, objetos y atributos con referencia casi exclusiva al trabajo de extracción y elaboración del nitrato ${ }^{6}$. Esa jerga ya no existe sino internalizada en individuos dispersos tras el desarme de las oficinas?.

2. Tal vez, el testimonio más vivo de ella, el que todavía nos habla y nos permite comunicarnos con el cosmos pampino desaparecido, se encuentra en la literatura, en los cuentos y novelas del salitreque, amorosamente, han sabido recrear no sólo la vida dolorosa de los mineros y sus familias, sino también importantes aspectos de su lengua, sobre todo aquellos que dicen relación con la forma de proyectarse en el mundo, a través de la imaginación. En la literatura de la pampa salitrera esas formas lingüísticas permanecen vivas en las bocas de personajes y narradores y desde el interior de los textos nos siguen hablando de sus angus-

\footnotetext{
${ }^{5}$ Entre 1888 y 1918 el salitre fueel principal motor dela economía chilena. El crecimiento de su comercio fue espectacular. Atraídos por la perspectiva de un trabajo bien remunerado, miles de hombres emigraron desde el valle central y el N orte Chico hacia las salitreras. Entre 1875 y 1907 la población del Norte Grande aumentó de 2.000 a 234.000 personas (Collier y Sater 1998: 150).

${ }^{6}$ El vocabulario pampino ha sido recogido por varios investigadores (Bertrand [1919], Echeverría y Reyes [1929], Bahamonde [1978], Araya et al. [1982], Lehnert [1997], González Miranda [2002].

${ }^{7}$ En encomiabley productivo esfuerzo, G onzález M iranda ha realizado una serie de entrevistas a sobrevivientes de las antiguas salitreras deTarapacá, verdadera labor de salvataje de un habla en extinción. Un extracto de esas entrevistas se incluye como anexo a su magnífico libro ya citado [313 y ss.]
} 
tias y esperanzas. Esto, a pesar de los procesos de selección y ficción quetodo texto literario implica. $Y$ es que la literatura opera siempre como signo y metasigno cultural: es construcción demundo identificable con una región y, al mismo tiempo, espejo en el que la propia región se reconoce, se distancia, se interroga y se cuestiona.

En la geografía literaria de C hile, el Ilamado N orte Grande ha sido objeto de poemas y relatos, en buena medida pertenecientes a escritores de otras zonas que, en ocasiones, visitaron o habitaron por períodos limitados al guna ciudad 0 poblado nortino. Así, D aniel Riquelme, Federico Gana, Baldomero Lillo, Carlos PezoaV éliz, Eduardo Barrios, G abriela M istral, Ernesto M ontenegro, Víctor Domingo Silva, Salvador Reyes, Pablo N eruda, Nicomedes Guzmán, Volodia Teitelboim, entre muchos, dejaron sus impresiones sobre el paisaje y las gentes del norte. Existe también una producción literaria propia, de gente que nació o se avecindó definitivamente en la región. Esta producción, salvo contadas excepciones, es muy poco difundida y peor conocida por los lectores chilenos. Aun la crítica especializada ha visto con cierto desdén y ligereza las páginas de muchos de estos escritores que, si bien es verdad, en su mayoría, sólo tiene un valor testimonial, tal vez histórico, no dejan de constituir formas válidas de aproximarse a la realidad nortina y de configurar en su conjunto una especie de mapa imaginario de la zona.

El relato salitrero tiene manifestaciones tempranas en los avatares de la $G$ uerra del Pacífico y comienza a adquirir su propia fisonomía con los albores del siglo $X X^{8}$. Se trata, en general, de una narrativa testimonial, autobiográfica, ingenuamente realista y a menudo viciosa en su estructura y estilo. D esde la periferia, que significa el N orte Grande como zona cultural chilena, los narradores siguen, en general, las tendencias y los moldes de la narración canónica nacional y latinoamericana9. La crítica sobre la narrativa de la pampa salitrera es

\footnotetext{
${ }^{8}$ Pedro Bravo Elizondo y Bernardo G uerrero Jiménez [2000], que, desde la U niversidad Arturo Prat y la W ichita StateU niversity, respectivamente, han venido realizando una notable faena de pesquisas destinada a rastrear documentos y testimonios literarios y socioculturales, salvándolos del olvido o extravío, en procura de ir diseñando el verdadero rostro cultural del N orte G rande, han rescatado la que, según el autorizado juicio de Guerrero, sería la primera novela editada en I quique, publicada en 1903. Se trata de Tarapacá, novela escrita, según M ario Bahamonde[1966], por 0 svaldo López y N icanor Polo, disimulados tras el sugestivo seudónimo deJ uanito Zola. La novelita "provocó escozor en la burguesía iquiqueña [...] no por el tema obrero, sino por los comentarios íntimos" que la afectaban y, entonces, compró toda la edición y la sepultó en el olvido. Véase tb. Guerrero Jiménez (2002).

${ }^{9} \mathrm{En} 1907$ se publican las Leyendas pampinas, firmadas nada menos que por T. D. M onio; en 1930, Corazón de pampino, de René Rubén; en 1932, Carnalavaca. N ovela de las tierras rojas, de Andrés $G$ arafulic y Jaibón, de D avid Rojas G onzález; en 1934, El secreto de losídolos, deT iburcio Lema M itchell.
} 
escasa, superficial, casi exclusivamente temática. En general, los pocos estudios existentes aluden fragmentariamente a cuestiones biográficas, anecdóticas, argumentales y vinculadas a la realidad social o política de la pampa. Incluso, la crítica a la obra de H ernán Rivera Letelier, que constituye un verdadero suceso de ventas, ediciones y traducciones, no escapa a este carácter. C asi siempre se trata de reseñas biobibliográficas y apreciaciones impresionistas que no van más de allá de exal tar ciertos aspectos de los relatos. Esfuerzos críticos loables y excepcionales son los de M oretic [1962], Bahamonde [1969] y Bravo Elizondo y Guerrero Jiménez [2000].

La escritura de la pampa sal itrera registra, testimonia y transforma la real idad del desierto y de los campamentos: ora la muestra con afán de denuncia, ora la evoca como forma de recuperarla amorosamente más allá de la muerte real. Se pueden señalar, provisionalmente, tres momentos fundamentales en su proceso narrativo: 1. El relato naturalista, testimonial, biográfico, documental, con personajes planos, a menudo tipificaciones, con importantes referencias a la geografía inhóspita y a la cruda real idad social; 2 . El relato neorrealista en el que los conflictos sociales se presentan en una escritura artística, tanto por el cuidado del lenguaje, como por la disposición narrativa, preocupada de ordenamientos, clímax, gradaciones, caracterización de personajes, etc.; 3. El relato postmoderno, evocativo, a veces elegíaco, paródico, humorístico en el quelosaspectos de denuncia aparecen suavizados por la visión memoriosa y, a veces, tierna del narrador y los hechos reales, convertidos a episodios donde prolifera la dimensión imaginaria. Esta tendencia está dominada por la escritura de H ernán Rivera Letelier.

La perspectiva de la narración naturalista (entre 1900 y 1930, aproximadamente) alude a la cultura pampina en su período de vigencia, contradictoria, conflictiva (v. Gr.: Tarapacá, de López y Polo, Carnalavaca, deG arafulic, Jaibón, de Rojas $G$ onzález) ${ }^{10}$; el punto de mira neorrealista (1940-1970 más o menos) asume la crisis de esa sociedad y adopta una mirada cronística, histórica eincluso legendaria (v. gr: Calichey pampinos ${ }^{11}$ de Luis González Zenteno, N orteG rande, de Andrés Sabella ${ }^{12}$, los cuentos y novelas cortas de $M$ ario Bahamonde ${ }^{13} 0$ Pisagua e H ijo del salitre de VolodiaTeitelboim). El relato posmoderno (las no-

10 Se inscriben en esta tendencia, novelas escritas por otros escritores chilenos, como Tamarugal (1944), de Eduardo Barrios o Pampa trágica (1921) y Palomita blanca (1923) de Víctor D omingo Silva, así como el relato "El taita de la oficina", de C arlos Pezoa V éliz.

${ }^{11}$ Guerrero Jiménez (2002) ha extraído un glosario de voces nortinas desde las novelas de González Zenteno, G uzmán y Barrios.

12 N orte Grande ha sido estudiada, entre otros, por Arán Faúndez, Luis (1974 y 1975) y Maya 1988.

${ }^{13}$ Sobre la narrativa deM ario Bahamonde, véase el documentado estudio deM aya (1998). 
velas de H ernán Rivera Letelier), a partir de los años 90, añora y mitifica. Pero en todos ellos se va construyendo un imaginario pampino que supone algunas constantes semánticas, determinados núcleos de sentido que los unifican y les dan un cierto carácter de especificidad narrativa. Esto no quiere decir que la visión de la pampa y del pampino que surge de los textos literarios constituya una mirada estereotipada y fija. Al contrario, las distintas tendencias narrativas, coincidentes con etapasimportantes del proceso social y cultural queviven las oficinassalitreras, permiten configurar, en cada momento, las imágenes dinámicas del pampino y su mundo, las transformaciones que va sufriendo el ser humano y con ello su cultura. Así, por ejemplo, el pampino de los inicios, en su mayoría migrante 'enganchado' desde el sur del país, muestra un permanente desasosiego por volver a sus paisajes nativos. Con el tiempo, los deseos de regreso se tornan en amarga desesperanza, en resignación, es esfuerzo estoico por endurecer la piel y el ánimo. Así, en "El taita de la oficina", de Pezoa Véliz. La novela de los años 30, en cambio, asume una visión distinta, más comprensiva de los procesos transformativos que va experimentando la oficina y la complejización de su vida social. Para los campesinos migrantes, lo que partió siendo una situación transitoria, un sacrificio útil que les permitiría volver a su tierra, acabó convirtiéndose en una opción definitiva: formaron familias, llegaron los hijos, nacidos en la pampa, enterraron a sus deudos. Vieron crecer el pueblo, se organizaron en mancomunales y filarmónicas, tuvieron escuelas, iglesias, mercados (pulperías), sus cantinas (pensiones o posadas), sus cines; experimentaron el reemplazo de la tecnología, el fin de las faenas y el cierre de muchas oficinas, así como la apertura de otras tantas; en fin, crearon formas de vida que los identificaron como pampinos. Así, en las novelas de G onzález Zenteno, Sabella, Bahamonde o Teitelboim.

La mirada de Rivera Letelier, en fin, corresponde a quien contempla el mundo pampino desde las ruinas de sus pueblos fantasmas, en un porfiado esfuerzo por sobrevivir, como aquellas sociedades y cofradías de los antiguos moradores de las oficinas que en los puertos aledaños tratan de repetir los ritos de una cultura ya desaparecida. La Reina I sabel cantaba rancheras (1994) es una verdadera elegía a la vida triste y dolorosa, no obstante entrañable, de las oficinas en decadencia, en que las picarescas y procaces historias de prostitutas se ordenan en función de la muerte de la principal de ellas y de los grotescos ritos funerarios, no exentos de ternura, de sus compañeras y amigos ${ }^{14}$; $\mathrm{H}$ imno del ángel parado en una pata (1996) encarna la añoranza de la (propia) niñez pampina, transformada en sueño fantasmal que abre y clausura el relato: "El hombre, con

\footnotetext{
14 “EI texto de Rivera -señala Rodrigo Cánovas- puede situarse con propiedad en el ámbito del grotesco bachtiniano, por cuanto se constituye como la celebración popular de las miserias de un cuerpo bendito" [1997: 65].
} 
una piedra redonda como una canica, reanuda los gol pes en la puerta de esa casa en escombros de aquella vieja salitrera abandonada..." [2001: 8]. A su vez, Fatamorgana de amor con banda de música [1998] recrea nostalgiosamente la vida 'alegre' del único pueblo libre del desierto salitrero: Pampa U nión; mientras, L os trenes se van al purgatorio (2000) configura una impresionante metáfora del retorno imposible, del gran espejismo que oculta la certeza de la muerte inevitable:

... a ambos lados de la línea férrea comienzan a dibujarse los cascotes de al gunas oficinas salitreras abandonadas. Junto a sus ruinas, como flotando a la deriva en la reverberación de las arenas candentes, ondulan susviejos cementerios de tumbas abiertas.

Y mientras su corazón en delirio es perforado por el silbato del tren al ejándose, prosiguiendo su irreal itinerario por las ciento cuarenta y dos estaciones espectrales, sus ojos dolorosos miran desvanecerse en el aire, en la ardua luz de la pampa, la silueta transparente, ilusoria, melancólica, del último vagón (2000: 169 y 191).

Por fin, Santa M aría de las flores negras (2002) vuelve a contar la historia de la matanza de 1907, en I quique, que tantos chilenos conocimos y cantamos, según la versión de Luis Advis, interpretada por el Q uilapayún.

Uno de los el ementos fundamentales de la cultura salitrera, omnipresentes en las novelas de Rivera Letelier, lo constituye, como no, el ámbito físico: el desierto, la pampa, los cerros, el sol, el viento, las huellas, las piedras, el caliche, la tierra, el polvo, la noche pampina. 0 tro núcleo semántico de importancia se relaciona con el hombre pampino, sus rasgos físicos y síquicos, las relaciones laborales, los oficios, el espíritu solidario, el carácter reservado, su estoicismo, la atracción por la aventura, etc. Un tercer campo semántico se vincula al prostíbulo y a la cantina [Cf. Cánovas 1997: 65 y 2003: 180-181]. H ay todavía otros tópicos importantes: la lucha social y las matanzas obreras; las creencias religiosas y supersticiones, los vínculos amorosos y familiares; las relaciones entre el pampino y el habitante de los puertos o de la precordillera, etc. De especial significación es la inventiva, apoyada en fantasmagorías, alucinaciones, espejismos, relatos de aparecidos o de extraviados.

Entre los recursos caracterizadores del universo pampino juega un papel fundamental el lenguajey, dentro de él, su componente léxico. Todos los narradores ponen especial hincapié en los procedimientos vinculados a la imitación del habla de los personajes, cada cual desde su respectiva tendencia y posición estética. $Y$ es que la riqueza creativa del habla pampina no se oculta a ninguno de ellos. Pero, claro, el habla salitrera no funciona sólo con este léxico restringido, 
sino con todo el idioma español, mestizado por el cruce de culturas que, desde un comienzo, implicó la explotación del nitrato: voces quechuas ${ }^{15}$, peruanas, bolivianas y chilenas de distintas regiones fueron integrando el amasijo semántico con el que los pampinos se entendieron con el mundo y entre ellos. A ese español veteado deben añadirse los préstamos de la lengua inglesa ${ }^{16}$, que pronto adquirieron ciudadanía pampina, adaptando sussignificadosy produciendo todo tipo de derivaciones.

Como toda jerga, la salitrera se construye, básicamente, sobre la base de préstamos y adaptaciones léxicas orientadas a satisfacer las necesidades comunicativas y onomasiológicas de la comunidad. En tal sentido, el espacio físico, el tipo de trabajo, la estructura social, la vida ciudadana, vivienda, costumbres y entretenciones, las formas dealimentación y vestuario, etc., van segregando nombres y expresiones característicos y raigalmente vinculados a la cultura del salitre. Así, expresiones como: abrónicos (barriles que servían de letrinas), achillarse (animarse), buque (habitación de solteros), cachero (encargado de enmangar herramientas), cachorrear (tronar pequeños tiros), cachucho (caldera para disolver el caliche), calchilla (mendigo), canario (pagador), cancho (remuneración extra), cangalla (robos de mineral), cantina (pensión, posada), cesante (re emplazante del marido ausente), chuscas (prostitutas), costrero (vigilante que evita costras en el acopio), crucible (crisol), cuico (boliviano), culero (parcheen la parte posterior del pantalón), chalala (ojota), chanchero (encargado de alimentar las chancadoras), chango (aborigen de la costa nortina), choca (colación), doblar el asta (dormirse), empampado (extraviado o aquerenciado en el desierto), encobar (errar los tiros), ficha (sustituto del dinero), gallo (suplente), gallar, gallero (operario ocasional), gallada (jornal que se paga al reemplazante), galleta (despedir a un operario), golondrinas (perforadoras), guaguas (perforadoras más grandes), jaibón (ricachón, de clase alta), landra (grieta), landroso (agrietado), longino (tren longitudinal), Ilavera (cocinera), machar (triturar), maucho (gente del sur), matasapo (muchacho que aplasta las costras de sal itre), moño (sobrecarga), muchacho (puntal), ñato (revólver), ñoco (hoyo), pique (pozo), pulguero (calabozo), pulpería (almacén), quisco (cuchilla), recova (verdulería), saca (muestra), sal natrón (mezcla de salitre y carbón), suple (adelanto

${ }^{15}$ Son préstamos del quechua: Callapo, acallapado, acallaparse; cacharpas, cacharpiarse; chancaca, achillado, achillarse, achancacado; apir, achullador; caliche, calichal; camanchaca, camanchaquero; calichera, calichoso; cancha, canchador, canchoso; circar, colpa; chanca, chancador, cacadora, chancar; chaya, chuca chullador, chullar, chullero; chupe; lampa, landra, locro, llampo, palla, pampapoquio, quisca, yapa, etc.

${ }^{16} \mathrm{C}$ rucible, chute, donkero, flanges, grillas, guachimán, huinche, huinchero, jaibón, lonche, Ionchero, paipas, parolistas, tender, tulipas, etc. 
de sueldo), tablas (grietas), troca (punzón), volcada (revuelta), zorro (puente rodante), zorrero (guardagujas), etc., existan o no en otras áreas etnolingüísticas, poseen en la jerga salitrera un significado restringido a su cultura ${ }^{17}$.

3. La irrupción deR ivera Letelier en el escenario de la narrativa chilena halogrado remecer en algún grado el ambiente crítico chileno y, especialmente, ha conquistado rápida y gratamente a una importante legión de lectores de novelas, no sólo en el país, sino en A mérica L atina y Europa. Sus relatos han experimentado sucesivas ediciones e importantes traducciones a varios idiomas. Si se tiene en cuenta que, hasta hace unos pocos años, Rivera Letelier era un perfecto desconocido, un minero, sobreviviente del cese de faenas, cierre de campamentos y hasta desarmaduría y rapiña de las oficinas sal itreras, el hecho puede considerarse un verdadero fenómeno. Sus novelas, aparte del éxito de ventas, ofrecen una absoluta novedad respecto de la producción anterior, pues se inscriben en las tendencias actuales de la narrativa latinoamericana, recreando, por un lado, un cierto realismo fantástico, a la manera de $G$ arcía $M$ árquez y, por otro, configurando un relato 'menor', sobre la base de historias vividas o contadas o extraídas de diversos medios, correspondientes a culturas subordinadas, discriminadas y heterodoxas.

Sus relatos tienen como escenario los pueblos pampinos u oficinas sal itreras en los cruciales tiempos de la crisis del nitrato y, por consiguiente, en la inminencia de su desaparición como hábitat. $N$ inguna de las novelas se sitúa en el cenit de la producción sal itrera o en la bullente actividad ciudadana delas oficinas. En la precariedad de las postrimerías, Rivera Letelier instala extraños personajes que provocan un airecillo farsesco, un aliento de carnaval en las horas más próximas al miércoles de ceniza. El humor, a veces un poco grueso, la teatralidad de situaciones y personajes, la bonhomía que irradia la voz narrativa consiguen sacar al relato de la pampa de la gravedad un poco acartonada delos narradores demasiado ideologizados o demasiado críticos que convertían a sus historias en alegatos y denuncias que conmovían pero terminaban por aburrir al lector. Las novelas de Rivera Letelier, sin escabullir la defensa de valores sociales, construyen un universo rico en matices y en episodios insólitos capaces de romper la monotonía gris y demasiado seria de sus predecesoras. El atractivo de sus relatos radica, en buena medida, en la proximidad (cercanía, familiaridad, naturalidad) con que los narradores - a menudo pobladores del lugar- cuentan sus historias: práctica ejercida desde la precariedad del sujeto marginal, desde un habla popular, socarrona; una retórica hiperbólica, barroca y carnavalesca; una visión que, no obstante la condición miserable de la vida narrada, no exenta de

${ }^{17}$ Guerrero Jiménez (2002) contiene un "G losario popular nortino de voces y lugares" en las novelas de Luis González Zenteno, N icomedes G uzmán y Eduardo Barrios. 
violencia, reafirma la dignidad de la condición humana, en su capacidad de resistencia, de ternura, de humanidad.

Por eso y no obstante sus significativas diferencias respecto a los anteriores cultores del relato de la pampa, Rivera Letelier es fiel en la construcción de su mundo novelesco a la tradición literaria pampina y a su propia experiencia en un aspecto crucial: el aquerenciamiento o empampamiento de los pobladores de las oficinas, que convierte al desierto en pampa, es decir, en morada habitable y añorada, en territorio de vida a pesar de lo implacable de su faz terrible. A pesar del "sol del carajo", deese "polvo demierda" y delas condiciones de explotación en las que vivió permanentemente el pampino, se produce un extraño sentimiento que oscila entre el odio y el amor, entrela maldición y la querencia. Finalmente, el paisaje estéril gana la partida; la pampa los atrapa y los cobija:

Al principio el paisaje nos golpeó tan crudamente el alma, que nos habíamos sentido trasplantados a las sequedades sulfurosas de un planeta ajeno. Sin embargo, poco a poco habíamos venido aprendiendo a querer estos páramos miserables, a mirar y admirar su áspera belleza de mundo a medio cocer. H abíamos ido descubriendo su alma oculta, como el tornasolado color mineral de los cerros, por ejemplo; o la diafanidad prodigiosa de sus cielos nocturnos, siempre ahítos de estrellas y de luminosidades misteriosas. 0 como este crepúsculo teñido de arreboles que ahora mismo teníamos frente a nosotros y que era como si el sol hubiese estallado en una explosión cósmica justo al llegar a la raya del horizonte... [2002: 50].

Este sentimiento contradictorio es esencial a la identidad pampina. D e este modo, Rivera Letelier se inserta en la tradición cultural literaria pampina, pero la renueva y al hacerlo recupera para la narrativa chilena y latinoamericana el ámbito de la pampa como lugar propicio a las más variadas e incrébles historias, desde una perspectiva postmoderna y mestiza ${ }^{18}$.

\section{REFEREN CIAS}

Arán Faúndez, Luis. 1973. N orte Grande, novela de espacio. M emoria para optar al grado de profesor de Castellano, $U$. del $N$ orte.

------ . 1974. "Función del espacio en N orte Grande, de Andrés Sabella",

Cuadernos de Filología (U. de C hile. Sede Antofagasta) 1: 45-66.

18 “... el postmodernismo latinoamericano es, hasta cierto punto, un nuevo relato de las marginalidades y la fragmentación, donde se reconstruye la identidad de lo heteróclito (el proceso de formar parte de la diferencia?)" [O rtega 1998: 37]. 
Araya, Angel et al. 1982. M uestra cartográfica y glosario del léxico del salitre, Antofagasta, U niversidad del Norte.

Arenas, Patricia y Andrea M astrangelo. 1987. "A puntes sobre el uso del concepto de región en losestudios sociales", en J. Kaliman (ed.), M emorias deJ ALLA Tucumán 1995, Tucumán, U niversidad N acional deTucumán, t. II: 92-107.

Bahamonde S., M ario. 1969. "El relato literario en el norte de Chile", en M . 0 stria González (ed.), La naturaleza y el hombre en la novela hispanoamericana, Primer Seminario Internacional de Literatura $\mathrm{H}$ ispanoamericana, Santiago, U niversidad del Norte.

-----1 . 1978. Diccionario de voces del norte de Chile, Santiago, N ascimento; 2a. Antofagasta, U niversidad Católica del N orte, 1998.

Bertrand, Alejandro. 1919. "Vocabulario pampino salitrero", Caliche, 6.

Bravo Elizondo, Pedro y Bernardo Guerrero Jiménez. 2000. H istoria y ficción literaria sobre el ciclo salitrero en Chile, I quique, Universidad Arturo Prat.

Cánovas, Rodrigo. 1997. N ovela chilena. N uevas generaciones: el abordajedelos huérfanos, Santiago, EUCCh

Collier, Simon y W illiam F. Sater. 1999. Historia de Chile. 1808-1994, M adrid, Cambridge U niversity Press.

Echeverría y Reyes, Aníbal. 1926. Voces usadas en la industria salitrera, Antofagasta, Imprenta Skarnic.

G onzález M iranda, Sergio. 2002. H ombres y mujeres dela pampa. Tarapacá en el ciclo de expansión del salitre, Santiago, Lom/DIBAN/UAP.

Guerrero Jiménez, Bernardo. 2002. Están reventando las rosas Sociedad y literatura en el N orte Grande de Chile, Iquique, U. Arturo Prat.

Larraín, Jorge. 2001. I dentidad chilena, Santiago, Lom.

Lehnert Santander, Roberto. 1997. D iccionario de léxico salitrero, Antofagasta, U niversidad de Antofagasta.

M aya, O svaldo. 1988. N orte Grande, novela lírica del mundo del salitre, Antofagasta, Ediciones del Taller Literario Recital.

$----\ldots$. 1998. M ario Bahamonde, novelista. Literatura y conciencia histórica del norte chileno, Antofagasta, Ediciones U niversitarias U CN .

M oretic. Yerko. 1962. El relato de la pampa salitrera, Santiago, Ediciones del Litoral.

O rtega, Julio. 1998. El principio radical de lo nuevo. Postmodernidad, identidad y nove la en América Latina, Lima, FCE, 2a

Rivera L etelier, H ernán. 2000. La reina I sabel cantaba rancheras, Santiago, Planeta, 5a [1994].

- - - . 2001. H imno del ángel parado en una pata, Santiago, Planeta, 6a [1996].

- - - . 1999. Fatamorgana de amor con banda de música, Santiago, Planeta, 3a (1998].

- - - . 2001. Los trenes se van al purgatorio, Santiago, Planeta, 5a [2000]

- - - . 2002. Santa M aría de las floresnegras, Buenos Aires, Seix Barral.

Sabella, Andrés. 1966. N orte G rande. 1866-1936, Santiago, 0 rbe, 3a D efinitiva.

Sepúlveda Llanos, Fidel. 2000. "La oralidad tradicional, un discurso estético alternativo de la identidad frente a la globalización", en VV. AA. Crisis, apocalipsisy uto- 
pías. Fines de siglo en la literatura latinoamericana, Santiago, Pontificia U niversidad Católica de Chile: 442-6.

Teitelboim, Volodia, 2002. Hijo del salitre, Santiago, Lom, 3a reimpr.

Vergara Estévez. 2003. "A proximacionesal concepto deidentidad cultural", en Vergara del Solar, A. y J. Bustos Troncoso (comp.), Esa oscura vida radiante. Juventud, infancia y nuevas identidades culturales, Concepción, Escaparate. 